\title{
Quercetin reduces systolic blood pressure and plasma oxidised low-density lipoprotein concentrations in overweight subjects with a high-cardiovascular disease risk phenotype: a double-blinded, placebo-controlled cross-over study
}

\author{
Sarah Egert ${ }^{1}$, Anja Bosy-Westphal ${ }^{1}$, Jasmin Seiberl ${ }^{1}$, Claudia Kürbitz ${ }^{1}$, Uta Settler ${ }^{1}$, \\ Sandra Plachta-Danielzik ${ }^{1}$, Anika E. Wagner ${ }^{2}$, Jan Frank ${ }^{2}$, Jürgen Schrezenmeir ${ }^{3}$, Gerald Rimbach ${ }^{2}$, \\ Siegfried Wolffram ${ }^{4}$ and Manfred J. Müller ${ }^{1 *}$ \\ ${ }^{1}$ Institute of Human Nutrition and Food Science, Department of Human Nutrition, Christian-Albrechts-University Kiel, 24105 Kiel, \\ Germany \\ ${ }^{2}$ Institute of Human Nutrition and Food Science, Department of Food Science, Christian-Albrechts-University Kiel, 24118 Kiel, \\ Germany \\ ${ }^{3}$ Max Rubner-Institute, Federal Research Institute of Nutrition and Food, 24103 Kiel, Germany \\ ${ }^{4}$ Institute of Animal Nutrition, Physiology and Metabolism, Christian-Albrechts-University Kiel, 24118 Kiel, Germany
}

(Received 26 January 2009 - Revised 25 March 2009 - Accepted 27 March 2009 - First published online 30 April 2009)

Regular consumption of flavonoids may reduce the risk for CVD. However, the effects of individual flavonoids, for example, quercetin, remain unclear. The present study was undertaken to examine the effects of quercetin supplementation on blood pressure, lipid metabolism, markers of oxidative stress, inflammation, and body composition in an at-risk population of ninety-three overweight or obese subjects aged $25-65$ years with metabolic syndrome traits. Subjects were randomised to receive $150 \mathrm{mg}$ quercetin/d in a double-blinded, placebo-controlled cross-over trial with 6 -week treatment periods separated by a 5 -week washout period. Mean fasting plasma quercetin concentrations increased from 71 to $269 \mathrm{nmol} / 1$ $(P<0.001)$ during quercetin treatment. In contrast to placebo, quercetin decreased systolic blood pressure $(\mathrm{SBP})$ by $2.6 \mathrm{mmHg}(P<0 \cdot 01)$ in the entire study group, by $2.9 \mathrm{mmHg}(P<0.01)$ in the subgroup of hypertensive subjects and by $3.7 \mathrm{mmHg}(P<0.001)$ in the subgroup of younger adults aged 25-50 years. Quercetin decreased serum HDL-cholesterol concentrations $(P<0 \cdot 001)$, while total cholesterol, TAG and the LDL:HDL-cholesterol and TAG:HDL-cholesterol ratios were unaltered. Quercetin significantly decreased plasma concentrations of atherogenic oxidised LDL, but did not affect TNF- $\alpha$ and C-reactive protein when compared with placebo. Quercetin supplementation had no effects on nutritional status. Blood parameters of liver and kidney function, haematology and serum electrolytes did not reveal any adverse effects of quercetin. In conclusion, quercetin reduced SBP and plasma oxidised LDL concentrations in overweight subjects with a high-CVD risk phenotype. Our findings provide further evidence that quercetin may provide protection against CVD.

Quercetin: Blood pressure: Inflammation: Oxidised LDL: CVD

Flavonoids in general and quercetin in particular have been associated with a decreased risk for $\mathrm{CVD}^{(1)}$. Furthermore, there was a trend towards a reduction in the incidence of type 2 diabetes mellitus at higher quercetin intakes ${ }^{(2)}$. In Western populations, the primary dietary sources of quercetin are tea, red wine, fruits and vegetables ${ }^{(3,4)}$. Quercetin is one of the major flavonoids, ubiquitously distributed in (edible) plants, and one of the most potent antioxidants of plant origin ${ }^{(1)}$. Numerous biological effects of quercetin, including antioxidant, anti-inflammatory, anti-thrombotic and vasodilatory actions, have been described in vitro ${ }^{(1)}$. However, quercetin intervention trials in human subjects have so far shown inconclusive and even conflicting results ${ }^{(5)}$. Quercetin supplementation increased plasma antioxidant capacity, ex vivo resistance of LDL to oxidation and resistance of lymphocyte DNA to strand breakage, but decreased urinary 8-hydroxy-2'-deoxyguanosine concentrations ${ }^{(5)}$. Other human studies, however, failed to confirm effects on these biomarkers ${ }^{(5)}$. A recent meta-analysis of 133 controlled flavonoid trials ${ }^{(6)}$ suggested that there may be clinically relevant effects of some flavonoids or flavonoid-rich foods on CVD risk factors. Most of the trials, however, used flavonoid-rich products rather than isolated flavonoids. Thus, it remained unclear whether the observed effects could be attributed to the individual flavonoids. In addition, an optimal dose of specific flavonoids for cardiovascular protection could not be determined.

In respect of the CVD risk factors blood pressure, flow-mediated dilatation and blood lipids, the main focus of attention to date has been made on flavonoids from cocoa (for example, catechin, epicatechin) and soya ${ }^{(6)}$.

Abbreviations: CRP, C-reactive protein; DBP, diastolic blood pressure; hs, high-sensitivity; SBP, systolic blood pressure.

* Corresponding author: Professor Manfred James Müller, fax +49 431 8805679, email mmueller@nutrfoodsc.uni-kiel.de 
Dark chocolate and cocoa appear to reduce flow-mediated dilatation acutely and reduce both systolic blood pressure (SBP) and diastolic blood pressure (DBP) after chronic intake $^{(6)}$. Soya protein isolate significantly reduced DBP and LDL-cholesterol concentrations ${ }^{(6-8)}$.

In a previous study, we had demonstrated that daily supplementation of normal-weight volunteers with 50, 100 or $150 \mathrm{mg}$ quercetin dose-dependently increased plasma quercetin concentrations but did not significantly affect selected risk parameters for CVD in these healthy subjects ${ }^{(9)}$, in whom a protective effect of quercetin was unlikely to occur. Thus, the aim of the present intervention study was to investigate the effects of quercetin supplementation on cardiovascular risk factors and biomarkers such as blood pressure, body composition, redox status, inflammation and blood lipids in overweight and obese subjects with a high-CVD risk phenotype. Another aim was to assess the safety of daily quercetin supplementation.

\section{Subjects and methods}

\section{Subjects}

Participants were recruited from the Kiel Obesity Prevention Study (KOPS) cohort $^{(10)}$ and the community of the city of Kiel, Germany, by notice-board postings, flyers and writing to families that are continuously followed up as a KOPS sub-cohort. From a total of 400 interested subjects, 172 subjects aged $25-65$ years with a BMI $25-35 \mathrm{~kg} / \mathrm{m}^{2}$ attended a screening which included physical assessments (height, body weight, blood pressure, pulse, waist and hip circumference), clinical assessments (liver function, serum lipids, glucose and uric acid, haematology, high-sensitivity (hs) C-reactive protein (CRP)), medical anamneses and dietary questionnaire.

Participants were included who had the following traits of the metabolic syndrome: (1) central obesity (waist circumference $\geq 94 \mathrm{~cm}$ for men and $\geq 80 \mathrm{~cm}$ for women); (2) serum concentration of $\mathrm{TAG} \geq 1500 \mathrm{mg} / \mathrm{l} \quad(1.7 \mathrm{mmol} / \mathrm{l})$; and/or (3) serum concentration of hs-CRP $\geq 2.0 \mathrm{mg} / \mathrm{l}$. Exclusion criteria were: smoking, insulin-dependent diabetes mellitus, liver, gastrointestinal or inflammatory diseases, a history of cardiovascular events, abnormal thyroid function, use of antiobesity medications, dietary supplements, anti-inflammatory drugs, cancer, recent major surgery or illness, pregnancy or breast-feeding, alcohol abuse, participation in a weight-loss programme, necessity for a medically supervised diet or $>5 \mathrm{~kg}$ weight loss within the 3 months before the study.

Ninety-six subjects (forty-two male, fifty-four female) were included into the study. Two subjects dropped out because they found the study protocol too demanding and one subject was excluded due to gastrointestinal symptoms. Only data from those ninety-three participants (forty-two male, fifty-one female) who completed the entire intervention study were included in the analysis and are subsequently reported.

The study was conducted according to the guidelines laid down in the Declaration of Helsinki and all procedures involving human subjects were approved by the ethical committee of the Medical Faculty of the Christian-Albrechts-University of Kiel, Germany. Written informed consent was obtained from all subjects.
Advice was given to the subjects to maintain their habitual diet, physical activity levels, lifestyle factors, and to maintain a stable body weight. Participants taking oral contraceptives ( $n 14 ; 27.5 \%$ of women), or antihypertensive ( $n 15 ; 16.1 \%$ ) or lipid-lowering drugs ( $n 3 ; 4.3 \%$ ), were instructed to continue taking their medications.

\section{Study design}

The study was undertaken as a double-blinded, randomised, placebo-controlled cross-over trial with 6-week (42d) treatment periods separated by a 5-week washout period. Subjects were instructed to take a total of six capsules per $\mathrm{d}$, two capsules with each principal meal. Capsules were distributed with a surplus of $10 \%$. The hard gelatine capsules contained quercetin dihydrate (Voigt Global Distribution Inc., Lawrence, KS, USA), mannitol and the flow-regulating excipient silicium dioxide. The capsules were produced at the Institute of Pharmacy, Johannes Gutenberg-University, Mainz, Germany (Dr Peter Langguth). A quercetin dosage of $150 \mathrm{mg} / \mathrm{d}$ was selected to represent the 15 -fold of the estimated daily quercetin intake in Germany of about $10 \mathrm{mg}^{(3,4)}$. Bioavailability of this quercetin dosage was examined in our previous study ${ }^{(9)}$.

Subjects were assigned to placebo or quercetin groups by blocked randomisation procedure, separately for men and women. Capsules (quercetin or placebo) were handed out at days 0 and 21 of each treatment period and leftovers were collected at days 21 and 42. Compliance was monitored by determining quercetin plasma concentrations (see below), by capsule count at the end of the study and by instructing subjects to document capsule consumption, observed side-effects, deviations from their normal physical activity, or any other observations considered relevant in a study diary.

Subjects were instructed to keep $3 \mathrm{~d}$ food records at baseline and end of the treatment arms of the study. Each record represented the food intake of 2 weekdays and 1 weekend day. These dietary records were used to calculate the habitual dietary energy and nutrient intake.

Sample size was calculated based on expected changes in TNF- $\alpha$. The power calculation revealed that ninety-four subjects had to complete the study to reach a $99 \%$ power to detect a $0.5 \mathrm{pg} / \mathrm{ml}$ difference in TNF- $\alpha$ concentrations between the placebo and quercetin groups at $P<0 \cdot 001^{(11)}$.

Anthropometry, body composition, resting blood pressure and pulse rate

Body height was determined on a stadiometer to the nearest $0.5 \mathrm{~cm}$ during the first examination. All other parameters listed below were measured on days 0,21 and 42 of each intervention period. On these days, participants were asked to visit the study unit in the early morning after an overnight fast.

For waist and hip measurements, participants were asked to roll down their undergarments. Waist circumference was measured to the nearest $0.5 \mathrm{~cm}$ midway between the lowest rib and the iliac crest, while the subject was at minimal respiration. Hip circumference was measured at the height 
of the greater trochanters. Both measurements were performed in duplicate in an upright position.

Body composition (fat mass and fat-free mass) was determined by air-displacement plethysmography using the BOD POD Body Composition System (Life Measurements Instruments, Concord, CA, USA), which is composed of a plethysmograph, an electronic scale and a personal computer (BOD POD software, version 2.14). A detailed description of the measurement is given elsewhere ${ }^{(12)}$. Body weight was determined to the nearest gram. Overweight $\left(B M I \geq 25-29.99 \mathrm{~kg} / \mathrm{m}^{2}\right)$ and obesity $\left(\mathrm{BMI} \geq 30 \cdot 0 \mathrm{~kg} / \mathrm{m}^{2}\right)$ were classified according to the WHO's criteria for adults $^{(13)}$.

Blood pressure measurements were obtained with a standard manual sphygmomanometer under standardised conditions according to the recommendations of the American Heart Association Council on High Blood Pressure Research $^{(14)}$. Each participant sat quietly for 5-10 min, after which their arm was placed at heart level, and SBP and DBP were measured at least twice in 3-5 min intervals. If blood pressure measurements varied by $\geq 10 \mathrm{mmHg}$, an additional measurement was performed. The accumulated measurements were then averaged to determine overall SBP and DBP. Pulse pressure (or blood pressure amplitude) was calculated as the pressure difference between SBP and DBP. Resting pulse rate was measured by hand palpation at the radial artery. All measurements were performed by the same trained investigator.

\section{Blood sampling}

Fasting venous blood samples were taken at the first and last day of the treatment arms. All samples were taken between 07.00 and 08.30 hours after an overnight fast under standardised conditions. The subjects abstained $24 \mathrm{~h}$ from alcohol and were told not to engage in strenuous exercise on the day before blood sampling. The last two capsules were taken about $12 \mathrm{~h}$ before blood sampling. Blood was drawn into tubes containing EDTA, lithium heparin, or no additives (Sarstedt, Nümbrecht, Germany). Plasma and serum were obtained by centrifugation at $2000 \mathrm{~g}$ for $15 \mathrm{~min}$ at $4^{\circ} \mathrm{C}$. Samples of plasma and serum were immediately frozen and stored in gas-tight cryovials at $-75^{\circ} \mathrm{C}$ until analysis. Clinical safety and haematological parameters (see below) were assayed from fresh samples within $3 \mathrm{~h}$ after venepuncture. All laboratory measurements were performed without knowledge of the treatment.

\section{Clinical safety parameters and haematological measurements}

Serum alanine transaminase, aspartate transaminase, $\gamma$-glutamyltranspeptidase, alkaline phosphatase, cholesteryl esterase as well as serum concentrations of creatinine, $\mathrm{K}$ and $\mathrm{Na}$ were determined using enzymic methods with a Konelab 20i analyser (Kone, Espoo, Finland). Haematological parameters (leucocyte count, erythrocyte count, platelet count, $\mathrm{Hb}$ concentration, packed cell volume, mean corpuscular volume, mean corpuscular haemoglobin and mean corpuscular hemoglobin concentration) were determined by using a CELL-DYN 3700 autoanalyser (Abbott Diagnostics Europe, Wiesbaden, Germany).

\section{Serum lipid parameters, glucose and uric acid}

Serum concentrations of total cholesterol, LDL-cholesterol, HDL-cholesterol and TAG as well as glucose and uric acid were measured using the Konelab 20i analyser (Kone) with the manufacturer's assay kits, quality controls and reagents.

\section{Plasma high-sensitivity $T N F-\alpha$}

Plasma concentrations of TNF- $\alpha$ were determined with the use of a high-sensitive ELISA (R\&D Systems, Europe Ltd, Abingdon, Oxon, UK) according to the manufacturer's instructions. The limit of detection was $0.106 \mathrm{pg} / \mathrm{ml}$ (information supplied by the manufacturer of the kit).

\section{Serum high-sensitivity $C$-reactive protein}

Serum concentrations of CRP were measured using an automated high-sensitivity IMMULITE two-site chemiluminescent enzyme immunometric assay (Immulite System; Diagnostic Products Corp., Los Angeles, CA, USA). The limit of detection was $0 \cdot 1 \mathrm{mg} / \mathrm{l}$.

\section{Plasma oxidised low-density lipoprotein}

Circulating oxidised LDL was determined using a commercial ELISA kit (Immundiagonstik AG, Bensheim, Germany) according to the manufacturer's protocol. The limit of detection was $4 \cdot 13 \mathrm{ng} / \mathrm{ml}$.

\section{Antioxidant capacity of plasma}

The antioxidant capacity of plasma was determined with the oxygen radical absorbance capacity in a ninety-six-well plate according to a modified method of Cao et al. ${ }^{(15)}$. $2,2^{\prime}$-Azobis(2-amidinopropan) was used to generate peroxyl radicals, trolox served as the control and sodium fluorescein as the fluorescent probe. In brief, $25 \mu \mathrm{l}$ of blank, trolox standard or acetone-precipitated plasma sample were mixed with $250 \mu \mathrm{l}$ sodium flourescein and incubated at $37^{\circ} \mathrm{C}$ for $10 \mathrm{~min}$. Subsequently, $25 \mu \mathrm{l} 2,2^{\prime}$-azobis(2-amidinopropan) solution were added and fluorescence was detected at excitation wavelength $485 \mathrm{~nm}$ and emission wavelength $520 \mathrm{~nm}$ every $1 \mathrm{~min}$ for $50 \mathrm{~min}$. Oxygen radical absorbance capacity values were calculated by the area under the curve.

\section{Plasma flavonoids}

Analyses of plasma concentrations of quercetin, its monomethylated derivative isorhamnetin ( $3^{\prime}-O$-methyl quercetin) and of kaempferol were performed by HPLC with fluorescence detection as described previously ${ }^{(16)}$. All samples were treated enzymically with $\beta$-glucuronidase/sulfatase type H-2 (crude enzyme extract from Helix pomatia; Sigma-Aldrich AG, Taufkirchen, Germany) before the extraction of the flavonols. Authentic flavonols (Carl Roth $\mathrm{GmbH}$, Karlsruhe, Germany) were used as external standards. 


\section{Statistical analysis}

All statistical analyses were performed using the SPSS statistical software package (version 15; SPSS Inc., Chicago, IL, USA). Distribution of data was analysed by checking histograms and normal plots of the data, and normality was tested by means of Kolmogorov-Smirnov and Shapiro-Wilk tests. Baseline characteristics of the groups were compared by means of independent-sample $t$ tests or Mann-Whitney $U$ tests. Comparison of normally distributed data between groups was performed using the unpaired Student's $t$ test and within a group using the paired Student's $t$ test. Data that were not normally distributed were compared using the Mann-Whitney $U$ and Wilcoxon signed ranks tests. Relationships between variables were evaluated using Pearson's correlation coefficient. In all cases, a value for $P \leq 0.05$ (two-sided) was taken to indicate a significant effect. Unless otherwise indicated, results are expressed as mean values and standard deviations. A test for carry-over effects according to Kenward \& Jones ${ }^{(17)}$ was used. No carry-over effects between the two treatment periods could be observed.

\section{Results}

\section{Baseline characteristics, compliance and dietary intake}

Baseline characteristics of the study subjects at screening are presented in Table 1 for the group as a whole and for men and women separately. Due to selection criteria all subjects were overweight $(45.2 \%)$ or obese $(54.8 \%)$. We observed sex differences with respect to body height, body weight, waist circumference, waist:hip ratio, fasting serum concentrations of hs-CRP, HDL-cholesterol, TAG and uric acid (Table 1).

Compliance with treatment, determined by counting the returned capsules and evaluation of the daily records, was high: 97.9 and $98.1 \%$ during quercetin and placebo consumption, respectively, and was not significantly different between the treatment groups and periods. Quercetin plasma concentrations were similar in both treatment groups at baseline and compliance with quercetin supplementation was confirmed by a marked increase in plasma quercetin concentrations by $349 \%(P<0.001)$ in subjects taking quercetin, but not placebo capsules (Fig. 1). We observed high inter-individual variation in plasma quercetin concentrations before (the range for all study subjects was $28.6-466.7 \mathrm{nmol} / \mathrm{l}$ ) and after supplementation (placebo group range: $18.6-334.3 \mathrm{nmol} / \mathrm{l}$; quercetin group range: $43 \cdot 2-740 \cdot 9 \mathrm{nmol} / \mathrm{l})$. The 5 -week washout period was sufficient to reduce plasma quercetin back to baseline values (data not shown). No significant sex differences in quercetin concentrations at baseline or after quercetin supplementation were observed.

Three-day dietary records were analysed in a randomised sample of fifty-two subjects and no significant differences between groups and within groups (comparing beginning and end of the treatment periods) in mean daily intakes of energy $(10.0 \mathrm{MJ} / \mathrm{d})$, protein $(15.4 \%$ energy intake), carbohydrates ( $43.4 \%$ energy intake), fat ( $37.8 \%$ energy intake), fatty acids, cholesterol, antioxidants (vitamin E, $1.3 \mathrm{mg} / \mathrm{MJ}$; vitamin $\mathrm{C}$, $11.8 \mathrm{mg} / \mathrm{MJ})$ or dietary fibre $(2.4 \mathrm{~g} / \mathrm{MJ})$ were observed.

\section{Safety parameters}

Biomarkers of liver and kidney function (alanine transaminase, aspartate transaminase, $\gamma$-glutamyl-transpeptidase, alkaline phosphatase, cholesteryl esterase, creatinine), haematology and serum electrolytes were all within normal ranges at all times and no differences were observed between the groups (data not shown).

\section{Body weight, waist circumference and body composition}

Quercetin supplementation did not significantly affect body weight, waist circumference, fat mass or fat-free mass

Table 1. Subject characteristics and blood parameters at screening

(Mean values and standard deviations)

\begin{tabular}{|c|c|c|c|c|c|c|}
\hline & \multicolumn{2}{|c|}{ Total $(n$ 93) } & \multicolumn{2}{|c|}{ Women (n 51) } & \multicolumn{2}{|c|}{ Men ( $n$ 42) } \\
\hline & Mean & SD & Mean & SD & Mean & SD \\
\hline Age (years) & $45 \cdot 1$ & 10.53 & 43.6 & $10 \cdot 61$ & $47 \cdot 0$ & $10 \cdot 24$ \\
\hline Body height (m) & 1.73 & 0.01 & 1.66 & 0.06 & $1 \cdot 81^{\star \star \star}$ & 0.07 \\
\hline Body weight $(\mathrm{kg})$ & 91.74 & $14 \cdot 38$ & 84.98 & $12 \cdot 26$ & $99 \cdot 96^{\star \star \star}$ & 12.43 \\
\hline $\mathrm{BMI}\left(\mathrm{kg} / \mathrm{m}^{2}\right)$ & $30 \cdot 6$ & $3 \cdot 23$ & $30 \cdot 8$ & 3.34 & $30 \cdot 4$ & $3 \cdot 12$ \\
\hline Overweight (\%) & \multirow{2}{*}{\multicolumn{2}{|c|}{$\begin{array}{l}45 \cdot 2 \\
54 \cdot 8\end{array}$}} & \multirow{2}{*}{\multicolumn{2}{|c|}{$\begin{array}{l}43 \cdot 2 \\
56 \cdot 8\end{array}$}} & \multirow{2}{*}{\multicolumn{2}{|c|}{$\begin{array}{l}47 \cdot 6 \\
52 \cdot 4\end{array}$}} \\
\hline Obese (\%) & & & & & & \\
\hline Waist circumference $(\mathrm{cm})$ & $104 \cdot 3$ & $9 \cdot 19$ & $100 \cdot 4$ & $8 \cdot 33$ & $109 \cdot 2^{\star \star \star}$ & $7 \cdot 84$ \\
\hline Waist:hip ratio & 0.94 & 0.08 & 0.90 & 0.06 & $1.01^{\star \star \star}$ & 0.05 \\
\hline $\mathrm{SBP}(\mathrm{mmHg})$ & $130 \cdot 3$ & $16 \cdot 4$ & $128 \cdot 5$ & $17 \cdot 3$ & 132.5 & $15 \cdot 1$ \\
\hline $\mathrm{DBP}(\mathrm{mmHg})$ & $81 \cdot 6$ & $9 \cdot 3$ & $80 \cdot 8$ & $9 \cdot 8$ & 82.5 & $8 \cdot 7$ \\
\hline Fasting serum glucose $(\mathrm{mmol} / \mathrm{l})$ & $5 \cdot 3$ & 0.55 & $5 \cdot 3$ & 0.50 & $5 \cdot 3$ & 0.60 \\
\hline Fasting serum hs-CRP (mg/l) & $4 \cdot 1$ & $5 \cdot 2$ & $5 \cdot 6$ & $6 \cdot 4$ & $2 \cdot 4^{\star \star *}$ & $2 \cdot 1$ \\
\hline Fasting serum total cholesterol $(\mathrm{mmol} / \mathrm{l})$ & $5 \cdot 81$ & 1.04 & 5.73 & 0.96 & 5.92 & $1 \cdot 13$ \\
\hline Fasting serum LDL-cholesterol (mmol/l) & 3.38 & 0.92 & $3 \cdot 30$ & 0.84 & 3.47 & 1.01 \\
\hline Fasting serum HDL-cholesterol (mmol/l) & 1.43 & 0.45 & $1 \cdot 61$ & 0.45 & $1 \cdot 20^{\star \star *}$ & 0.34 \\
\hline Fasting serum TAG $(\mathrm{mmol} / \mathrm{l})$ & $2 \cdot 23$ & $1 \cdot 18$ & 1.82 & 0.81 & $2 \cdot 73^{\star \star \star}$ & 1.36 \\
\hline Fasting serum uric acid $(\mu \mathrm{mol} / \mathrm{l})$ & $351 \cdot 4$ & 92.5 & $310 \cdot 1$ & 85.39 & $399 \cdot 7^{\star \star \star}$ & $76 \cdot 21$ \\
\hline
\end{tabular}

SBP, systolic blood pressure; DBP, diastolic blood pressure; hs-CRP, high-sensitivity C-reactive protein.

${ }^{\star \star \star}$ Mean value was significantly different from that of women $(P<0.001$; Mann-Whitney $U$ test). 

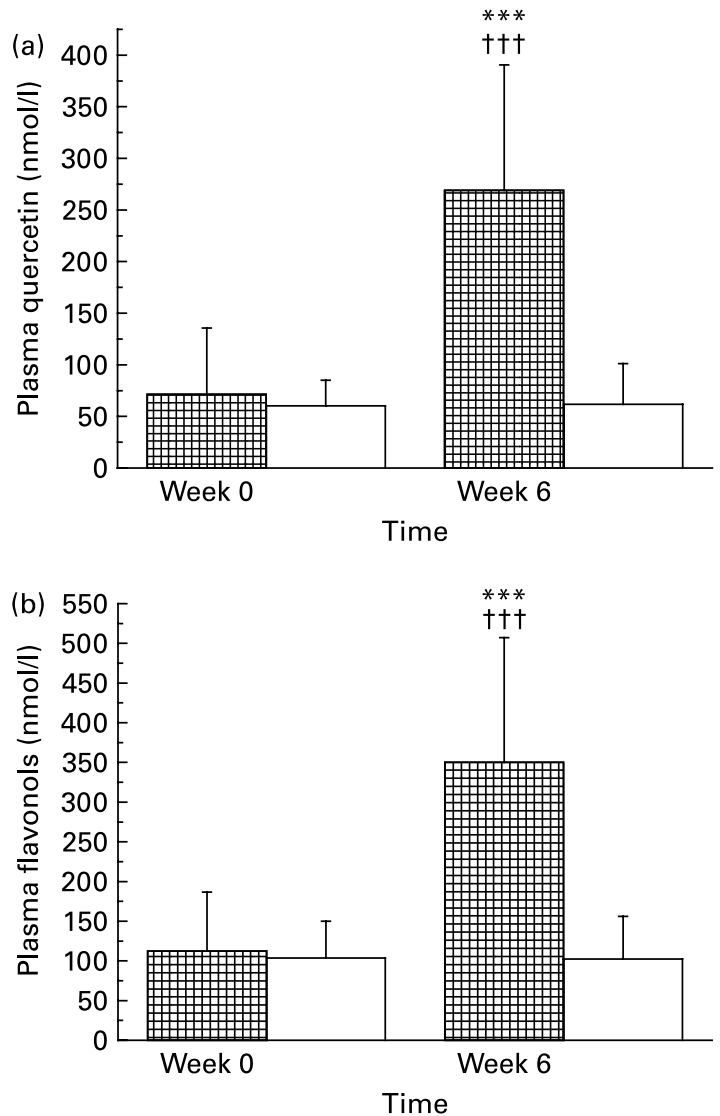

Fig. 1. Plasma concentrations of quercetin (a) and total flavonols (b) in human subjects before and after 6-week supplementation with quercetin (150 mg/d; 焑) or placebo $(\square)$. Values are means, with standard deviations represented by vertical bars. ${ }^{* \star *}$ Mean value was significantly different from that at baseline $(P<0.001$; intra-group comparison; Wilcoxon test). tt† Change during quercetin treatment was significantly different from that during placebo treatment $(P<0.001$; inter-group comparison; Mann-Whitney $U$ test). The two groups did not differ significantly with regard to quercetin or flavonol concentrations at baseline (Mann-Whitney $U$ test). Total plasma flavonols were calculated according to: total flavonols $(\mathrm{nmol} / \mathrm{l})=$ quercetin $(\mathrm{nmol} / \mathrm{l})$ plus kaempferol $(\mathrm{nmol} / \mathrm{l})$ plus isorhamnetin $(\mathrm{nmol} / \mathrm{l})$. Note that the $y$ axes show different concentration ranges.

(data not shown). However, in women, there was a small decrease in fat mass $(-0.57(\mathrm{SD} 1.58) \mathrm{kg} ; P<0.05)$ and an increase in fat-free mass $(0.52$ (SD 1.26) $\mathrm{kg} ; P<0.01)$ in the placebo group, but no between-group differences in changes of body composition were observed (data not shown).

Resting blood pressure, pulse rate, serum lipids, glucose and uric acid

In contrast to placebo, quercetin supplementation significantly decreased SBP by $2.6(\mathrm{SD} 9.1) \mathrm{mmHg}(P<0.01)$ in the entire study group, by 2.9 (SD 9.5) $\mathrm{mmHg}(P<0.01)$ in the subgroup of (pre-)hypertensive subjects (defined as $\mathrm{SBP} \geq 120$ or $\left.\mathrm{DBP} \geq 80 \mathrm{mmHg}^{(18)}\right)$ and by $3.7(\mathrm{SD} 7.4) \mathrm{mmHg}(P<0.001)$ in the subgroup of younger adults aged $25-50$ years (Table 2 ). In the latter subgroup, the decrease from baseline was significantly different from the placebo group $(P<0 \cdot 05)$ (Table 2$)$.

Quercetin treatment significantly decreased pulse pressure in the total study group, in (pre-)hypertensive subjects and in the subgroup of younger adults (Table 2). Resting pulse rate did not significantly change during quercetin treatment (Table 2).

Quercetin supplementation did not significantly affect serum concentrations of total cholesterol, TAG, glucose or uric acid (Table 3). Serum concentrations of LDL-cholesterol were significantly decreased by both quercetin and placebo treatment, but were not significantly different between groups (Table 3). Compared with placebo, quercetin significantly decreased HDL-cholesterol concentrations (Table 3). The LDL:HDL-cholesterol and TAG:HDL-cholesterol ratios were not significantly changed by quercetin or placebo treatment (Table 3).

\section{High-sensitivity $T N F-\alpha$, high-sensitivity $C$-reactive-protein, oxidised LDL and plasma antioxidant capacity}

Quercetin and placebo treatment significantly decreased serum concentrations of hs-TNF- $\alpha$ from baseline by 0.25 $(\mathrm{SD} 0.73) \mathrm{pg} / \mathrm{ml}(P<0.001)$ and by $0.08(\mathrm{SD} 0.87) \mathrm{pg} / \mathrm{ml}$ $(P<0.05)$, respectively. Changes from baseline were not significantly different between groups (Table 4). Neither quercetin nor placebo significantly altered serum concentrations of hs-CRP, as analysed for the total study group (Table 4) and separately for men and women (data not shown). However, in subjects with baseline hs-CRP concentrations $\geq 2 \mathrm{mg} / \mathrm{l}$, quercetin as well as placebo treatment significantly decreased hs-CRP by $2.35($ SD 11.20$) \mathrm{mg} / \mathrm{l}(P<0.01)$ and by 1.35 (SD 3.49$) \mathrm{mg} / \mathrm{l}(P<0 \cdot 01)$, respectively. These changes did not differ significantly between treatment groups.

Quercetin supplementation decreased serum concentrations of oxidised LDL by $170 \cdot 8$ (SD 328.5) ng/ml $(P<0.001)$. This change was significantly different $(P<0.05)$ from the decrease by $88.8(\mathrm{SD} 360.3) \mathrm{ng} / \mathrm{ml}(P<0.05)$ during placebo treatment (Table 4). No significant associations were found between circulating oxidised LDL concentrations and serum LDL-cholesterol or between oxidised LDL concentrations and biomarkers of inflammation (data not shown). The plasma oxygen radical absorbance capacity was not significantly affected by quercetin or placebo treatment (Table 4).

Correlations of blood pressure parameters, oxidised $L D L$, high-sensitivity $T N F-\alpha$ and high-sensitivity $C$-reactive protein with plasma quercetin concentrations

SBP, pulse pressure, plasma oxidised LDL concentrations, serum hs-TNF- $\alpha$ and serum hs-CRP concentrations were not significantly correlated with plasma concentrations of quercetin (data not shown).

\section{Discussion}

The aim of the present double-blinded, placebo-controlled, cross-over intervention study was to investigate the effect of a 6-week supplementation with quercetin $(150 \mathrm{mg} / \mathrm{d})$ on individuals with a high-cardiometabolic risk phenotype on established CVD risk biomarkers. Our major finding was that quercetin supplementation significantly reduced SBP. This effect was most pronounced in subjects aged 25-50 years. In addition, quercetin caused a significant reduction in plasma concentrations of atherogenic oxidised LDL. In contrast, there were no effects of quercetin on biomarkers 
Table 2. Resting systolic (SBP) and diastolic blood pressure (DBP), pulse pressure and pulse rate in human subjects before and after 6-week supplementation with quercetin $(150 \mathrm{mg} / \mathrm{d})$ or placebo $\neq$ (Mean values and standard deviations)

\begin{tabular}{llll}
\hline & Time & Mean & SD \\
\hline
\end{tabular}

Total

Quercetin ( $n$ 93)

$\mathrm{SBP}(\mathrm{mmHg})$

$\mathrm{DBP}(\mathrm{mmHg})$

Pulse pressure $(\mathrm{mmHg})$

Pulse rate (beats per min)

Placebo $(n$ 93)

$\mathrm{SBP}(\mathrm{mmHg})$

$\mathrm{DBP}(\mathrm{mmHg})$

Pulse pressure $(\mathrm{mmHg})$

Pulse rate (beats per min)

Normotensive subjects§

Quercetin $(n 17)$

SBP $(\mathrm{mmHg})$

$\mathrm{DBP}(\mathrm{mmHg})$

Pulse pressure $(\mathrm{mmHg})$

Pulse rate (beats per min)

Placebo $(n 20)$

$\mathrm{SBP}(\mathrm{mmHg})$

DBP $(\mathrm{mmHg})$

Pulse pressure $(\mathrm{mmHg})$

Pulse rate (beats per min)

(Pre-)hypertensive subjects||

Quercetin $(n 74)$

SBP $(\mathrm{mmHg})$

DBP $(\mathrm{mmHg})$

Pulse pressure $(\mathrm{mmHg})$

Pulse rate (beats per min)

Placebo $(n 71)$

SBP $(\mathrm{mmHg})$

DBP $(\mathrm{mmHg})$

Pulse pressure $(\mathrm{mmHg})$

Pulse rate (beats per min)

Group 25-50 years, no medications

Quercetin ( $n$ 48)

SBP $(\mathrm{mmHg})$

$\mathrm{DBP}(\mathrm{mmHg})$

Pulse pressure $(\mathrm{mmHg})$

Pulse rate (per min)

Endpoint $\quad 125.7 \quad 13.2$

$\begin{array}{lll}\text { Endpoint } & 82.8 & 8.2\end{array}$

$\begin{array}{lll}\text { Baseline } & 44.3 & 8.8\end{array}$

$\begin{array}{lll}\text { Endpoint } & 43.0 & 8.7\end{array}$

$\begin{array}{lll}\text { Baseline } & 72.6 & 8.5\end{array}$

Endpoint $\quad 74.6^{*} \dagger \quad 9.3$

Endpoint $\quad 109.9 \quad 8.5$

$\begin{array}{lll}\text { Baseline } & 71.8 & 3.7\end{array}$

Endpoint $\quad 73.6 \quad 7.3$

Baseline $\quad 39.2 \quad 5.0$

Endpoint $\quad 36.3 \quad 5.4$

Baseline $\quad 72.2 \quad 10.9$

Endpoint $\quad 75.5 \quad 8.5$

Baseline $\quad 111.8 \quad 5.0$

Endpoint $\quad 113.3 \quad 6.6$

$\begin{array}{lll}\text { Baseline } & 73.2 & 4.7\end{array}$

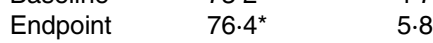

Baseline $\quad 38.6 \quad 5.1$

Endpoint $\quad 36.8 \quad 3.6$

Baseline $\quad 72.2 \quad 9.2$

$\begin{array}{lll}\text { Endpoint } & 75.0 & 9.1\end{array}$

Baseline $\quad 130.0 \quad 12.3$

Endpoint $\quad 127 \cdot 1^{\star *} \quad 12 \cdot 9$

$\begin{array}{lll}\text { Baseline } & 83.3 & 7.9\end{array}$

Endpoint $\quad 83.4 \quad 7.3$

$\begin{array}{lll}\text { Baseline } & 46.7 & 10.4\end{array}$

$\begin{array}{lll}\text { Endpoint } & 43.8^{* *} & 10.0\end{array}$

$\begin{array}{lll}\text { Baseline } & 76.1 & 8.8\end{array}$

$\begin{array}{lll}\text { Endpoint } & 73.8 & 8.7\end{array}$

Baseline $\quad 130.3 \quad 11.2$

Endpoint $\quad 129.1 \quad 12.5$

Baseline $\quad 84.4 \quad 8.2$

Endpoint $\quad 84.5 \quad 7.9$

Baseline $\quad 45.9 \quad 8.9$

Endpoint $\quad 44.6 \quad 8.9$

Baseline $\quad 72.7 \quad 8.4$

$\begin{array}{lll}\text { Endpoint } & 74.5 & 9.4\end{array}$

$9 \cdot 4$

Baseline $\quad 124.4$

$120 \cdot 7^{\star * \star} \dagger \quad 11.4$

$\begin{array}{lll}\text { Endpoint } & 79.6 & 8.4\end{array}$

Baseline $\quad 44.5 \quad 7.8$

Endpoint $\quad 41 \cdot 1^{\star *} \quad 6.5$

Baseline $\quad 78.3 \quad 10.0$ $\begin{array}{lll}\text { Baseline } & 82.0 & 8.9\end{array}$

Baseline $\quad 110.9 \quad 4.6$

Endpoint $\quad 76.4 \dagger \quad 7.5$
Mean value was significantly different from that at baseline: ${ }^{\star} P<0.05$, ${ }^{\star \star} P<0.01$, ${ }^{\star \star \star} P<0.001$ (intra-group comparison; Wilcoxon test).

$\dagger$ Change during quercetin treatment was significantly different from that during placebo treatment $(P<0.05$; Mann-Whitney $U$ test).

¥The two groups did not differ significantly with regard to blood pressure parameters and pulse rates at baseline (Mann-Whitney $U$ test).

§SBP $<120 \mathrm{mmHg}$ and DBP $<80 \mathrm{mmHg}$.

$\| \mathrm{SBP} \geq 120 \mathrm{mmHg}$ or DBP $\geq 80 \mathrm{mmHg}$.

Table 2. Continued

of inflammation and metabolism including body composition. We used a moderate supranutritional but non-pharmacological dose of quercetin, since these data should provide a rational basis for the development of functional foods.

\section{Blood pressure}

To the best of our knowledge, so far only two human studies have examined the effect of quercetin supplementation on arterial blood pressure ${ }^{(19,20)}$. Conquer et al. ${ }^{(19)}$ reported no changes in SBP or DBP when healthy volunteers (mean age 42 years) with mean baseline blood pressure of 122/ $79 \mathrm{mmHg}$ and a mean BMI of $26 \mathrm{~kg} / \mathrm{m}^{2}$ were supplemented with a high (non-nutritional) dosage of $1000 \mathrm{mg}$ quercetin/d for 8 weeks. In contrast, Edwards et al. ${ }^{(20)}$ recently found that 4-week supplementation with $730 \mathrm{mg}$ quercetin/d significantly reduced SBP $(-7 \mathrm{mmHg})$ and DBP $(-5 \mathrm{mmHg})$ in subjects with stage 1 hypertension but not in those with prehypertension. However, a non-significant reduction in blood pressure was also observed in the placebo group and the authors did not report significant differences between the quercetin and placebo groups. It was concluded that a certain degree of hypertension might be required for quercetin to exert a blood pressure-lowering effect.

Our data further indicate that age is an important factor for blood pressure-lowering effects of quercetin. We hypothesise that improved endothelial function might be the underlying mechanism that may act especially in younger and middle-aged individuals. In this group higher blood pressures are mainly caused by an increase in peripheral vascular resistance generated by functional and structural narrowing of the resistance arteries and arterioles. As age advances, structural damage and disease in larger conduit arteries become more important determinants of blood pressure. As atherosclerotic modifications of the vasculature, resulting in arterial stiffening and loss of vascular function, aggravate with $\mathrm{age}^{(21)}$, the potential to improve vascular function by nutrients declines.

Because endothelial dysfunction is critical in atherosclerosis and hypertension ${ }^{(22)}$, improving endothelium-dependent vasodilation is one possible mechanism by which flavonoids

\begin{tabular}{|c|c|c|c|c|c|c|}
\hline \multirow{2}{*}{\multicolumn{3}{|c|}{ cetin $(150 \mathrm{mg} / \mathrm{d})$ or placeboł }} & & Time & Mean & SD \\
\hline & & & Placebo ( $n$ 48) & & & \\
\hline \multirow{4}{*}{ Time } & & & $\mathrm{SBP}(\mathrm{mmHg})$ & Baseline & $123 \cdot 6$ & 11.9 \\
\hline & Mean & SD & & Endpoint & $123 \cdot 6 \dagger$ & 11.8 \\
\hline & & & $\mathrm{DBP}(\mathrm{mmHg})$ & Baseline & $80 \cdot 3$ & $9 \cdot 3$ \\
\hline & & & & Endpoint & $82 \cdot 1^{*}$ & 8.5 \\
\hline & 126.5 & & Pulse pressure $(\mathrm{mmHg})$ & Baseline & $43 \cdot 3$ & $7 \cdot 6$ \\
\hline Baseline & $126 \cdot 5$ & 13.5 & & Endpoint & 41.5 & $7 \cdot 1$ \\
\hline Endpoint & $123 \cdot 9^{\star x}$ & 14.0 & Pulse rate (per min) & Baseline & 74.4 & 9.9 \\
\hline Baseline & $81 \cdot 2$ & 8.5 & & Endpoint & $76 \cdot 7^{\star} \dagger$ & 8.4 \\
\hline Endpoint & $81 \cdot 6$ & $8 \cdot 2$ & & & & \\
\hline
\end{tabular}


Table 3. Fasting serum lipids and lipoproteins, serum glucose and serum uric acid in human subjects before and after 6-week supplementation with quercetin $(150 \mathrm{mg} / \mathrm{d})$ or placeboł

(Mean values and standard deviations)

\begin{tabular}{|c|c|c|c|c|c|}
\hline & \multirow[b]{2}{*}{ Time } & \multicolumn{2}{|c|}{ Quercetin ( $n$ 93) } & \multicolumn{2}{|c|}{ Placebo ( $n$ 93) } \\
\hline & & Mean & SD & Mean & SD \\
\hline \multirow[t]{2}{*}{ Serum total cholesterol $(\mathrm{mmol} / \mathrm{l})$} & Baseline & $5 \cdot 72$ & 1.03 & $5 \cdot 68$ & 1.05 \\
\hline & Endpoint & 5.63 & 1.03 & $5 \cdot 62$ & 1.02 \\
\hline \multirow[t]{2}{*}{ Serum LDL-cholesterol (mmol/l) } & Baseline & 3.59 & 0.97 & 3.55 & 0.94 \\
\hline & Endpoint & $3 \cdot 46^{*}$ & 0.90 & $3.44^{*}$ & 0.89 \\
\hline \multirow[t]{2}{*}{ Serum HDL-cholesterol (mmol/l) } & Baseline & 1.35 & 0.46 & 1.30 & 0.43 \\
\hline & Endpoint & $1 \cdot 28^{\star \star *} \dagger \dagger \dagger$ & 0.43 & 1.30††† & 0.44 \\
\hline \multirow[t]{2}{*}{ Serum TAG (mmol/l) } & Baseline & 1.82 & 0.98 & 1.95 & 0.99 \\
\hline & Endpoint & 1.94 & $1 \cdot 31$ & 1.83 & 0.99 \\
\hline \multirow[t]{2}{*}{ LDL-cholesterol:HDL-cholesterol ratio } & Baseline & 2.99 & 1.25 & 3.06 & 1.26 \\
\hline & Endpoint & 2.99 & 1.67 & 2.96 & $1 \cdot 18$ \\
\hline \multirow[t]{2}{*}{ TAG:HDL-cholesterol ratio } & Baseline & 1.64 & $1 \cdot 28$ & 1.78 & 1.27 \\
\hline & Endpoint & 1.88 & 1.87 & 1.70 & 1.38 \\
\hline \multirow[t]{2}{*}{ Serum glucose (mmol/l) } & Baseline & 5.49 & 0.68 & 5.44 & 0.70 \\
\hline & Endpoint & 5.46 & 0.70 & 5.49 & 0.69 \\
\hline \multirow[t]{2}{*}{ Serum uric acid $(\mu \mathrm{mol} / \mathrm{l})$} & Baseline & $294 \cdot 0$ & 87.44 & $294 \cdot 7$ & 84.63 \\
\hline & Endpoint & $292 \cdot 7$ & 85.63 & $300 \cdot 4$ & 93.19 \\
\hline
\end{tabular}

Mean value was significantly different from that at baseline: ${ }^{*} P<0.05,{ }^{\star \star \star} P<0.001$ (intra-group comparison; Wilcoxon test or paired $t$ test)

t†† Change during quercetin treatment was significantly different from that during placebo treatment $(P<0.001$; Mann-Whitney $U$ test or $t$ test).

$\ddagger$ The two groups did not differ significantly with regard to any of the variables at baseline (independent-sample $t$ test or Mann-Whitney $U$ test).

may reduce cardiovascular risk $^{(6)}$. The results of a recent placebo-controlled intervention study in healthy subjects (mean blood pressure of $123 / 78 \mathrm{mmHg}$ ) suggested that pure quercetin can improve endothelial function by modulating the circulating concentrations of vasoactive NO products and endothelin- $1^{(23)}$. These effects may be explained by inhibition of NADPH oxidase and the activation of endothelial NO synthase. In fact, acute treatment with $200 \mathrm{mg}$ quercetin increased endogenous NO (S-nitrosothiols, nitrite and nitrate) but reduced endothelin-1 production ${ }^{(23)}$.

In vitro studies about the vascular effects of quercetin showed that it may exert multiple actions on the NO-guanylyl cyclase pathway, endothelium-derived hyperpolarising factor(s) and endothelin-1 and protect endothelial cells against apoptosis ${ }^{(24)}$. In vivo, quercetin prevented endothelial dysfunction and reduced blood pressure, oxidative stress and end-organ damage in hypertensive animals ${ }^{(24)}$. Quercetin may exert its effect on endothelial function specifically when endothelial function is impaired and blood pressure is elevated.

Lifestyle modification has been emphasised in prehypertensive and hypertensive individuals as an initial intervention to control blood pressure ${ }^{(18)}$. The quercetin-induced reduction of blood pressure in our subjects was similar to the effects of $\mathrm{Na}$ reduction, increased physical activity, alcohol reduction $^{(18)}$ or fish oil supplementation ${ }^{(25)}$.

A potential limitation in the interpretation of our quercetin effects on SBP is the fact that we only measured the office blood pressure in the resting state. Future studies should integrate $24 \mathrm{~h}$ ambulatory blood pressure measurements with a total number of readings between 50 and 100 to reveal valid additional data about the effects of quercetin on mean $24 \mathrm{~h}$, daytime and night-time ambulatory blood pressure. Ambulatory blood pressure monitoring will therefore give a better description about the effects of daily quercetin supplementation than one-off office measurements.

Table 4. Serum high-sensitivity TNF- $\alpha$ (hs-TNF- $\alpha$ ), serum high-sensitivity C-reactive protein (hs-CRP), plasma oxidised LDL and plasma antioxidant capacity (ORAC) in human subjects before and after 6-week supplementation with quercetin $(150 \mathrm{mg} / \mathrm{d})$ or placeboł (Mean values and standard deviations)

\begin{tabular}{|c|c|c|c|c|c|}
\hline & \multirow[b]{2}{*}{ Time } & \multicolumn{2}{|c|}{ Quercetin (n 93) } & \multicolumn{2}{|c|}{ Placebo ( $n$ 93) } \\
\hline & & Mean & SD & Mean & SD \\
\hline \multirow[t]{2}{*}{ hs-TNF- $\alpha$ (pg/ml) } & Baseline & $2 \cdot 62$ & 2.40 & $2 \cdot 48$ & 2.37 \\
\hline & Endpoint & $2 \cdot 37^{\star \star \star}$ & 2.45 & 2.40 & $2 \cdot 50^{*}$ \\
\hline \multirow{2}{*}{ hs-CRP (mg/l) } & Baseline & 5.07 & 9.42 & 3.96 & 3.84 \\
\hline & Endpoint & $4 \cdot 15$ & $5 \cdot 72$ & 3.90 & 4.01 \\
\hline \multirow[t]{2}{*}{ Oxidised LDL (ng/ml) } & Baseline & $1192 \cdot 8$ & $668 \cdot 1$ & 1170.8 & $620 \cdot 2$ \\
\hline & Endpoint & $1021 \cdot 9^{\star \star \star} \dagger$ & 597.9 & $1082 \cdot 0^{*} \dagger$ & $609 \cdot 9$ \\
\hline \multirow{2}{*}{ ORAC value } & Baseline & 1.06 & 0.15 & 1.08 & 0.17 \\
\hline & Endpoint & 1.07 & 0.17 & 1.09 & 0.17 \\
\hline
\end{tabular}

Mean value was significantly different from that at baseline: ${ }^{\star} P<0.05$, ${ }^{* \star *} P<0.001$ (intra-group comparison; Wilcoxon test).

† Change during quercetin treatment was significantly different from that during placebo treatment $(P<0.05 ;$ Mann-Whitney $U$ test $)$

$\ddagger$ The two groups did not differ significantly with regard to any of the variables at baseline (Mann-Whitney $U$ test). 


\section{Atherogenic oxidised $L D L$}

Quercetin protects against free radical damage via scavenging activity in vitro ${ }^{(1)}$. In the light of a relatively low bioavailability and an intensive metabolic transformation of orally applied quercetin, however, a direct role of plasma quercetin as an in vivo antioxidant has been questioned ${ }^{(26)}$. Nevertheless, the present results showed that quercetin significantly reduced plasma concentrations of oxidised LDL. Conversion of LDL to oxidised LDL is considered to be a key event in atherogenesis ${ }^{(27)}$. Concentrations of oxidised LDL are increased in patients with the metabolic syndrome ${ }^{(28)}$ and are associated with obesity, dyslipidaemia and insulin resistance ${ }^{(29)}$. Increased oxidised LDL was predictive for future myocardial infarction ${ }^{(28,29)}$. Our finding is in line with Ruel et al. ${ }^{(30)}$ who showed that flavonoid-rich cranberry juice containing quercetin significantly decreased oxidised LDL concentrations in overweight subjects. In a recent cell-culture study quercetin and some of its major in vivo metabolites (for example, quercetin-3- $O$-glucuronide) inhibited neutrophil-mediated LDL oxidation at physiological concentrations $^{(31)}$. The presence of quercetin glucuronides in human atherosclerotic lesions further suggests that quercetin may be available to prevent LDL oxidation in vivo ${ }^{(32)}$. These results together with data from the present study support that quercetin may act as an antioxidant in vivo.

\section{Inflammation}

Quercetin has been shown to exert anti-inflammatory effects. Nair et al. ${ }^{(33)}$ showed that quercetin dose-dependently inhibited the gene expression and production of the proinflammatory cytokine TNF- $\alpha$ by peripheral blood mononuclear cells. This effect was explained by modulation of the NF- $\mathrm{B}$ signal transduction cascade. In obese Zucker rats, a high dose of quercetin $(10 \mathrm{mg} / \mathrm{kg}$ body weight $)$ improved the inflammatory status, as it decreased the production of TNF- $\alpha$ by the visceral adipose tissue, and increased the plasma concentrations of the anti-inflammatory adipocytokine adiponectin $^{(34)}$. Since obese and type 2 diabetes Zucker rats and obese humans are characterised by adipose tissue overproduction of pro-inflammatory cytokines such as TNF- $\alpha$ and by decreased plasma concentrations of anti-inflammatory adipocytokines such as adiponectin ${ }^{(35-37)}$, it is tempting to speculate that quercetin may affect serum levels of inflammatory cytokines.

In the present human study, quercetin had no antiinflammatory effect in overweight or obese subjects with a high-CVD risk phenotype. Although we found a significant decrease of serum hs-TNF- $\alpha$ during quercetin supplementation and also a significant decrease in hs-CRP in subjects with elevated baseline hs-CRP concentrations ( $\geq 20 \mathrm{mg} / \mathrm{l})$, both changes did not differ significantly between quercetin and placebo. These results are in line with the results in healthy normal-weight volunteers $^{(9,38)}$, where the lack of effect was probably due to the low cytokine and high antioxidant level at baseline, indicating that neither inflammation nor oxidative stress was present.

As the experimental studies including our previous findings in mice ${ }^{(39)}$ showed anti-inflammatory effects at high plasma quercetin concentrations $(>1 \mu \mathrm{M})^{(33,38)}$ or at a high supranutritional quercetin dosage (for example, $10 \mathrm{mg} / \mathrm{kg}$ body weight in obese rats) ${ }^{(34)}$, we speculate that a quercetin dosage of $150 \mathrm{mg} / \mathrm{d}(1.6 \mathrm{mg} / \mathrm{kg}$ body weight $)$ and the plasma quercetin concentrations of about $0 \cdot 3 \mu \mathrm{M}$ reached were too low to induce a significant anti-inflammatory effect.

\section{Metabolism}

Some flavonoids, particularly green-tea catechins such as epigallocatechin gallate, may affect energy metabolism. For example, in healthy normal-weight human subjects, consumption of green tea extracts has been shown to increase fatty acid oxidation and energy expenditure, particularly if combined with a metabolic stimulant such as caffeine ${ }^{(40-42)}$ and to reduce total and abdominal fat in subjects with visceral fat-type obesity ${ }^{(43)}$. However, in accordance with our previous study in healthy normal-weight subjects $^{(9)}$, we found no significant effects of quercetin on fat mass.

Quercetin has also been shown to have hypocholesterolaemic and hypotriacylglycerolaemic effects in animal studies ${ }^{(44,45)}$, but respective human studies conducted so far using quercetin supplements could not support these effects ${ }^{(9,19,20)}$. However, there are two human studies that showed an improvement in lipoprotein profiles during supplementation with concentrated red grape juice ${ }^{(46)}$ and lyophilised grape powder ${ }^{(47)}$, both rich in quercetin. In the present study, we found a small, but significant decrease in HDL-cholesterol during quercetin treatment. The decrease in HDL-cholesterol concentration, however, was not associated with an increase in the LDL:HDL-cholesterol or TAG:HDL-cholesterol ratios, respectively. Thus, we conclude, that the small decrease in HDL-cholesterol concentration during the quercetin supplementation might be of only limited, if any, physiological or clinical relevance.

The precise underlying molecular mechanism that may be responsible for the HDL-cholesterol-modulating effect by quercetin has not been elucidated up to now. Castilla et al. ${ }^{(46)}$ found that the increase in HDL-cholesterol concentration during flavonoid-rich grape juice consumption was paralleled by an increase in apo A1 concentrations. This indicates that flavonoids may affect hepatic apo A1 secretion in vivo, as described in a cell-culture study using HepG2 hepatocytes $^{(48)}$.

\section{Safety parameters}

As with any intervention, potential risk also must be considered. Our data suggest that the daily supplementation of $150 \mathrm{mg}$ quercetin aglycone by volunteers with a high-CVD risk phenotype for the duration of 6 weeks is safe.

In conclusion, the present study showed that dietary supplementation of the diet with $150 \mathrm{mg}$ quercetin/d significantly reduced SBP and plasma oxidised LDL concentrations in overweight subjects with a high-CVD risk phenotype. Our findings provide further evidence that quercetin may provide protection against CVD. Further studies are needed to confirm the physiological and clinical relevance of these results.

\section{Acknowledgements}

We thank Petra Schulz and Angelika Thoss for excellent technical assistance. 
The project was financially supported by the German Federal Ministry of Education and Research (BMBF 0313856A) within the project 'Functional Foods for Vascular Health - from Nutraceuticals to Personalised Diets'. None of the authors has any personal or financial conflicts of interest in the publication of this paper.

M. J. M. and G. R. provided funding. S. E. and M. J. M. designed the study. S. E., A. B.-W., J. S., C. K. and U. S. recruited the subjects and performed the study. S. P.-D. performed the blinding procedure. J. F. produced the capsules. S. E., J. S., C. K., U. S., A. E. W., J. S. and S. W. participated in data collection and analysis. S. E. performed the statistical calculations. S. E. and M. J. M. wrote the manuscript. G. R., S. W. and J. F. contributed to the final discussion of the results. All authors reviewed the final manuscript.

\section{References}

1. Erdman JW Jr, Balentine D, Arab L, et al. (2007) Flavonoids and heart health: Proceedings of the ILSI North America Flavonoids Workshop, May 31-June 1, 2005, Washington, DC. J Nutr 137, Suppl., 718S-737S.

2. Knekt P, Kumpulainen J, Jarvinen R, et al. (2002) Flavonoid intake and risk of chronic diseases. Am J Clin Nutr 76, $560-568$.

3. Linseisen J, Radtke J \& Wolfram G (1997) Flavonoidzufuhr Erwachsener in einem Bayrischen Teilkollektiv der Nationalen Verzehrsstudie (Flavonoid intake of adults in a Bavarian subgroup of the national food consumption survey). Z Ernahrungswiss 36, 403-412.

4. Böhm H, Boeing H, Hempel J, et al. (1998) Flavonols, flavone and anthocyanins as natural antioxidants of food and their possible role in the prevention of chronic diseases (article in German). Z Ernahrungswiss 37, 147-163.

5. Williamson G \& Manach C (2005) Bioavailability and bioefficacy of polyphenols in humans. II. Review of 93 intervention studies. Am J Clin Nutr 81, 243S-255S.

6. Hooper L, Kroon PA, Rimm EB, et al. (2008) Flavonoids, flavonoid-rich foods, and cardiovascular risk: a meta-analysis of randomized controlled trials. Am J Clin Nutr 88, 38-50.

7. Cassidy A, de Pascual TS \& Rimbach G (2003) Molecular mechanisms by which dietary isoflavones potentially prevent atherosclerosis. Expert Rev Mol Med 5, 1-15.

8. Rimbach G, Boesch-Saadatmandi C, Frank J, et al. (2008) Dietary isoflavones in the prevention of cardiovascular disease - a molecular perspective. Food Chem Toxicol 46, $1308-1319$.

9. Egert S, Wolffram S, Bosy-Westphal A, et al. (2008) Daily quercetin supplementation dose-dependently increases plasma quercetin concentrations in healthy humans. $J$ Nutr 138, 1615-1621.

10. Danielzik S, Czerwinski-Mast M, Langnase K, et al. (2004) Parental overweight, socioeconomic status and high birth weight are the major determinants of overweight and obesity in 5-7y-old children: baseline data of the Kiel Obesity Prevention Study (KOPS). Int J Obes Relat Metab Disord 28, 1494-1502.

11. Scales DC \& Rubenfeld GD (2005) Estimating sample size in critical care clinical trials. J Crit Care 20, 6-11.

12. Bosy-Westphal A, Danielzik S, Becker C, et al. (2005) Need for optimal body composition data analysis using air-displacement plethysmography in children and adolescents. J Nutr 135, 2257-2262.

13. World Health Organization (2000) Obesity: Preventing and Managing the Global Epidemic. WHO Technical Report Series no. 894. Geneva: WHO.
14. Pickering TG, Hall JE, Appel LJ, et al. (2005) Recommendations for blood pressure measurement in humans and experimental animals: Part 1: blood pressure measurement in humans: a statement for professionals from the Subcommittee of Professional and Public Education of the American Heart Association Council on High Blood Pressure Research. Hypertension 45, 142-161.

15. Cao G, Alessio HM \& Cutler RG (1993) Oxygen-radical absorbance capacity assay for antioxidants. Free Radic Biol Med 14, 303-311.

16. Bieger J, Cermak R, Blank R, et al. (2008) Tissue distribution of quercetin in pigs after long-term dietary supplementation. $J$ Nutr 138, 1417-1420.

17. Kenward MG \& Jones B (1987) The analysis of data from $2 \times 2$ cross-over trials with baseline measurements. Stat Med 6, 911-926.

18. Chobanian AV, Bakris GL, Black HR, et al. (2003) The Seventh Report of the Joint National Committee on Prevention, Detection, Evaluation, and Treatment of High Blood Pressure: the JNC 7 report. JAMA 289, 2560-2572.

19. Conquer JA, Maiani G, Azzini E, et al. (1998) Supplementation with quercetin markedly increases plasma quercetin concentration without effect on selected risk factors for heart disease in healthy subjects. J Nutr 128, 593-597.

20. Edwards RL, Lyon T, Litwin SE, et al. (2007) Quercetin reduces blood pressure in hypertensive subjects. J Nutr 137, $2405-2411$.

21. Williams B, Lindholm LH \& Sever P (2008) Systolic pressure is all that matters. Lancet 371, 2219-2221.

22. Landmesser U, Hornig B \& Drexler H (2004) Endothelial function: a critical determinant in atherosclerosis? Circulation 109, II $27-$ II 33 .

23. Loke WM, Hodgson JM, Proudfoot JM, et al. (2008) Pure dietary flavonoids quercetin and (-)-epicatechin augment nitric oxide products and reduce endothelin-1 acutely in healthy men. Am J Clin Nutr 88, 1018-1025.

24. Perez-Vizcaino F, Duarte J \& Andriantsitohaina R (2006) Endothelial function and cardiovascular disease: effects of quercetin and wine polyphenols. Free Radic Res 40, 1054-1065.

25. Morris MC, Sacks F \& Rosner B (1993) Does fish oil lower blood pressure? A meta-analysis of controlled trials. Circulation 88, 523-533.

26. Lotito SB \& Frei B (2006) Dietary flavonoids attenuate tumor necrosis factor $\alpha$-induced adhesion molecule expression in human aortic endothelial cells. Structure-function relationships and activity after first pass metabolism. J Biol Chem 281, 37102-37110.

27. Stocker R \& Keaney JF (2004) Role of oxidative modifications in atherosclerosis. Physiol Rev 84, 1381-1478.

28. Holvoet P, Kritchevsky SB, Tracy RP, et al. (2004) The metabolic syndrome, circulating oxidized LDL, and risk of myocardial infarction in well-functioning elderly people in the health, aging, and body composition cohort. Diabetes 53, 1068-1073.

29. Holvoet P (2008) Relations between metabolic syndrome, oxidative stress and inflammation and cardiovascular disease. Verh K Acad Geneeskd Belg 70, 193-219.

30. Ruel G, Pomerleau S, Couture P, et al. (2005) Changes in plasma antioxidant capacity and oxidized low-density ipoprotein levels in men after short-term cranberry juice consumption. Metabolism 54, 856-861.

31. Loke WM, Proudfoot JM, McKinley AJ, et al. (2008) Quercetin and its in vivo metabolites inhibit neutrophil-mediated low-density lipoprotein oxidation. J Agric Food Chem 56, 3609-3615.

32. Kawai Y, Nishikawa T, Shiba Y, et al. (2008) Macrophage as a target of quercetin glucuronides in human atherosclerotic 
arteries: implication in the anti-atherosclerotic mechanism of dietary flavonoids. J Biol Chem 283, 9424-9434.

33. Nair MP, Mahajan S, Reynolds JL, et al. (2006) The flavonoid quercetin inhibits proinflammatory cytokine (tumor necrosis factor $\alpha$ ) gene expression in normal peripheral blood mononuclear cells via modulation of the NF-кB system. Clin Vaccine Immunol 13, 319-328.

34. Rivera L, Moron R, Sanchez M, et al. (2008) Quercetin ameliorates metabolic syndrome and improves the inflammatory status in obese Zucker rats. Obesity (Silver Spring) 16, 2081-2087.

35. Hotamisligil GS, Arner P, Caro JF, et al. (1995) Increased adipose tissue expression of tumor necrosis factor- $\alpha$ in human obesity and insulin resistance. J Clin Invest 95, 2409-2415.

36. Esposito K, Nappo F, Giugliano F, et al. (2003) Meal modulation of circulating interleukin 18 and adiponectin concentrations in healthy subjects and in patients with type 2 diabetes mellitus. Am J Clin Nutr 78, 1135-1140.

37. Galisteo M, Sanchez M, Vera R, et al. (2005) A diet supplemented with husks of Plantago ovata reduces the development of endothelial dysfunction, hypertension, and obesity by affecting adiponectin and TNF- $\alpha$ in obese Zucker rats. $J$ Nutr 135, 2399-2404.

38. Boots AW, Wilms LC, Swennen EL, et al. (2008) In vitro and ex vivo anti-inflammatory activity of quercetin in healthy volunteers. Nutrition 24, 703-710.

39. Boesch-Saadatmandi C, Wolffram S, Minihane AM, et al. (2008) Effect of apoE genotype and dietary quercetin on blood lipids and TNF- $\alpha$ levels in apoE3 and apoE4 targeted gene replacement mice. $\mathrm{Br} J$ Nutr (Epublication ahead of print version 6 November 2008).

40. Berube-Parent S, Pelletier C, Dore J, et al. (2005) Effects of encapsulated green tea and guarana extracts containing a mixture of epigallocatechin-3-gallate and caffeine on $24 \mathrm{~h}$ energy expenditure and fat oxidation in men. Br J Nutr 94, $432-436$.

41. Dulloo AG, Duret C, Rohrer D, et al. (1999) Efficacy of a green tea extract rich in catechin polyphenols and caffeine in increasing 24-h energy expenditure and fat oxidation in humans. Am J Clin Nutr 70, 1040-1045.

42. Venables MC, Hulston CJ, Cox HR, et al. (2008) Green tea extract ingestion, fat oxidation, and glucose tolerance in healthy humans. Am J Clin Nutr 87, 778-784.

43. Nagao T, Komine $\mathrm{Y}$, Soga $\mathrm{S}$, et al. (2005) Ingestion of a tea rich in catechins leads to a reduction in body fat and malondialdehyde-modified LDL in men. Am J Clin Nutr 81, 122-129.

44. Igarashi K \& Ohmuma M (1995) Effects of isorhamnetin, rhamnetin, and quercetin on the concentrations of cholesterol and lipoperoxide in the serum and liver and on the blood and liver antioxidative enzyme activities of rats. Biosci Biotechnol Biochem 59, 595-601.

45. Yugarani T, Tan BK, Teh M, et al. (1992) Effects of polyphenolic natural products on the lipid profiles of rats fed high fat diets. Lipids 27, 181-186.

46. Castilla P, Echarri R, Davalos A, et al. (2006) Concentrated red grape juice exerts antioxidant, hypolipidemic, and antiinflammatory effects in both hemodialysis patients and healthy subjects. Am J Clin Nutr 84, 252-262.

47. Zern TL, Wood RJ, Greene C, et al. (2005) Grape polyphenols exert a cardioprotective effect in pre- and postmenopausal women by lowering plasma lipids and reducing oxidative stress. J Nutr 135, 1911-1917.

48. Theriault A, Wang Q, Van Iderstine SC, et al. (2000) Modulation of hepatic lipoprotein synthesis and secretion by taxifolin, a plant flavonoid. J Lipid Res 41, 1969-1979. 